\title{
Activation of endogenous neural stem cells for multiple sclerosis therapy
}

\author{
Iliana Michailidou ${ }^{1+}$, Helga E. de Vries ${ }^{2}$, Elly M. Hol ${ }^{1,3,4}$ and Miriam E. van Strien ${ }^{1,4 *}$ \\ Department of Astrocyte Biology and Neurodegeneration, The Netherlands Institute for Neuroscience, An Institute of the Royal Netherlands Academy of \\ Sciences, Amsterdam, Netherlands \\ ${ }^{2}$ Department of Molecular Cell Biology and Immunology, VU University Medical Center, Amsterdam, Netherlands \\ ${ }^{3}$ Center for Neuroscience, Swammerdam Institute for Life Sciences, University of Amsterdam, Amsterdam, Netherlands \\ ${ }^{4}$ Department of Translational Neuroscience, Brain Center Rudolf Magnus, University Medical Center Utrecht, Utrecht, Netherlands
}

\section{Edited by:}

João O. Malva, University of

Coimbra, Portugal

\section{Reviewed by:}

Fernando De Castro, Hospital

Nacional de Parapléjicos-SESCAM,

Spain

Djoher Nora Abrous, Institut des

Neurosciences de Bordeaux, France

Annalisa Buffo, University of Turin,

Italy

${ }^{*}$ Correspondence:

Miriam E. van Strien, Department of

Translational Neuroscience, Brain

Center Rudolf Magnus, University

Medical Center Utrecht, Stratenum,

Universiteitsweg 100, 3584 CG

Utrecht, Netherlands

e-mail:m.e.vanstrien@umcutrecht.nI

${ }^{\dagger}$ Present address:

Iliana Michailidou, Department of

Genome Analysis, Academic

Medical Center, Amsterdam,

Netherlands
Multiple sclerosis (MS) is a chronic inflammatory disorder of the central nervous system, leading to severe neurological deficits. Current MS treatment regimens, consist of immunomodulatory agents aiming to reduce the rate of relapses. However, these agents are usually insufficient to treat chronic neurological disability. A promising perspective for future therapy of MS is the regeneration of lesions with replacement of the damaged oligodendrocytes or neurons. Therapies targeting to the enhancement of endogenous remyelination, aim to promote the activation of either the parenchymal oligodendrocyte progenitor cells or the subventricular zone-derived neural stem cells (NSCs). Less studied but highly potent, is the strategy of neuronal regeneration with endogenous NSCs that although being linked to numerous limitations, is anticipated to ameliorate cognitive disability in MS. Focusing on the forebrain, this review highlights the role of NSCs in the regeneration of MS lesions.

\section{Keywords: multiple sclerosis, neurogenesis, gliogenesis, neural stem cells, therapy}

\section{INTRODUCTION}

Multiple sclerosis (MS) is a chronic inflammatory, demyelinating disease of the central nervous system (CNS) that has an important neurodegenerative component. The pathological hallmark of MS is the presence of demyelinating lesions (Noseworthy et al., 2000). MS was traditionally considered as a disease affecting only the white matter (WM) areas of the CNS; more recent studies however, showed extensive pathology also in the gray matter (GM) (Geurts and Barkhof, 2008).

MS development is linked to loss of the blood brain barrier (BBB) integrity and migration of autoreactive T-cells and monocytes (Sospedra and Martin, 2005; Hemmer et al., 2006; Vogel et al., 2013). Autoimmunity plays a central role in the disease pathogenesis either as the primary cause or as the consequence of an ongoing neurodegenerative process. Notably, several studies in post-mortem MS brain material and experimental autoimmune encephalomyelitis (EAE) indicated that key features of neurodegeneration, such as neuronal cell atrophy, axonal transection, and neuronal death, already occur in early disease phases (Trapp et al., 1998). The diffuse neuronal damage is associated with pronounced atrophy, decreased functional connectivity and cognitive decline in the majority of patients (Roosendaal et al., 2010).
The major clinical subtypes of MS are relapsing-remitting (RR) and secondary progressive (SP) MS. RR-MS represents the initial inflammatory phase of approximately $85-90 \%$ of all cases. SP-MS usually develops later in the disease course and is associated with axon degeneration (Lublin and Reingold, 1996). A less common progressive subtype is primary progressive (PP) MS. PPMS affects approximately $10 \%$ of all cases and manifests with no relapses but a steady decline in function from disease onset (Andersson et al., 1999).

For treatment of MS, during the past decades, attention was paid to the modulation of immune responses for prevention of axon demyelination. Immunomodulatory and anti-inflammatory agents can efficiently slow down RR-MS (and SP-MS to a certain extent) progression by reducing the frequency of relapses (Fischer et al., 2000; Barak and Achiron, 2002; Goodin et al., 2002). However, they do not improve disease outcome after degeneration occurs, and therefore are insufficient to treat chronic neurological disability in patients with progressive disease (Molyneux et al., 2000; Compston and Coles, 2002; Coles et al., 2006).

It is now known, that treatment of MS requires not only prevention, but also repair of the injury. Good candidates for the repair of MS lesions are the neural stem cells (NSCs), cells that retain their multipotential capacity in the adult and senescent 
brain (Van den Berge et al., 2010). In this review we will highlight the importance that regenerative capacity of endogenous NSCs has in future therapeutic options for MS.

\section{NEURAL STEM CELLS IN THE ADULT MAMMALIAN BRAIN}

NSCs are multipotent cells that have the ability to self-renew and differentiate into neurons or glial cells (Gage, 2000). Their production is mainly taking place at the neural tube of the developing brain (Wilson and Stice, 2006). NSCs persist in the adult brain, albeit in much lower densities, being also present in the brains of elderly and patients with a neurodegenerative disorder (Leonard et al., 2009; Van den Berge et al., 2010, 2011). In the adult brain, generation of NSCs is restricted in two highly specialized tissue niches: the subventricular zone (SVZ) of the lateral ventricles and the subgranular zone (SGZ) of the hippocampus (Gage et al., 1998; Quiñones-Hinojosa et al., 2007). Newborn NSCs enter an active phase of proliferation and/or differentiation once they receive stimulatory signals, such as growth factors produced by the surrounding cells (Gage et al., 1998; Sun et al., 2010). Differentiation of NSCs can result in the production of new neurons with neurogenesis, or glial cells with gliogenesis.

\section{NEUROGENESIS}

Animal studies have shown that NSCs generated at the adult hippocampal SGZ form new neurons which integrate in the dentate gyrus (Cameron and Gould, 1994) whereas, NSCs generated at the adult SVZ, form new interneurons which integrate in the olfactory bulb (OB) (Carleton et al., 2003). The adult human SVZ is characterized by a dense ribbon of glial fibrillary acidic protein (GFAP) positive astrocytes that lines the lateral wall of the lateral ventricles. This astrocyte ribbon is highly proliferative and clearly separated from the ependyma by a hypocellular gap layer (Nader Sanai, 2004).

New SVZ-derived neuroblasts which were differentiated from NSCs migrate to the OB through the rostral migratory stream (RMS) in rodents and non-human primates (Craig et al., 1999; Pencea et al., 2001a). In this stream, migrating neuroblasts build elongated chains that are tangentially oriented to the $\mathrm{OB}$, through glial tubes formed by astrocytes (Lois et al., 1996). In humans however, migration of neuroblasts is elusive; studies in the early postnatal brain described a primary corridor connecting the infant SVZ to the OB, and a branching stream that reaches the ventromedial prefrontal cortex (Sanai et al., 2011); studies in the adult human brain indicated the presence of the primary corridor only and described migration of a modest number of neuroblasts (Van Strien et al., 2011).

In MS, neurogenesis possibly occurs at the SVZ leading to generation of new immature neurons in a subgroup of chronic subcortical lesions (Chang et al., 2008). However, neurogenesis in the MS brain is reduced compared to healthy adult brain, leading to lower neuronal supply to the OB which might explain the often reported olfactory deficits in patients (Tepavčević et al., 2011).

\section{GLIOGENESIS}

In the developing brain gliogenesis follows neurogenesis but persists long after neurogenesis has ceased (Jacobson, 1991). Differentiation of glial progenitor cells results in the formation of astrocytes or oligodendrocytes (Lee et al., 2000).
Oligodendrogenesis in adulthood is restricted in and around the SVZ and involves the formation of an intermediate progenitor phenotype, the oligodendrocyte progenitor cell (OPC). OPCs are self-renewing cells that can reside in multiple areas of the adult healthy brain parenchyma until they get activated and differentiated (Menn et al., 2006). Differentiation of OPCs involves expression of specific markers, changes in cellular morphology and extension of endfeet toward the axons for myelination (Compston et al., 1997; Blakemore and Keirstead, 1999; Young et al., 2013).

In MS, loss of axon myelin is often followed by the remyelination of nude axons with new myelin sheaths. Remyelination is a naturally regulated process orchestrated by mature oligodendrocytes (Blakemore and Keirstead, 1999). This process is activated in response to acute demyelination and often leads to formation of shadow plaques, areas of complete repair activity, in otherwise intact white or gray matter. Remyelination activity is high in acute (average $80.7 \%$ of all lesions) and persists in chronic progressive MS (average $60 \%$ of all lesions). In the WM, remyelination occurs mainly in early inflammatory (Goldschmidt et al., 2009) and chronic active lesions (Patani et al., 2007), the latter being lesions surrounded by a sharp border of activated microglia/macrophages. For remyelination in MS, resident OPCs are recruited and differentiated into mature oligodendrocytes (Gensert and Goldman, 1997; Nait-Oumesmar et al., 1999); moreover, new oligodendrocyte lineage cells are produced by a two to three-fold activation of the adult SVZ in MS (NaitOumesmar et al., 2007) and EAE (Picard-Riera et al., 2002; Tepavčević et al., 2011).

\section{REMYELINATION BY PARENCHYMAL OPCs IN MS}

Remyelination, although activated in MS, is insufficient to repair severe and long-lasting demyelination events like the ones occurring in the progressive phases of the disease. The failure of remyelination to sufficiently restore chronic damage is not caused by the lesional depletion of OPCs (Wolswijk, 1998); instead, changes that can be induced at any of the four phases consisting the remyelination process, may reduce capacity of endogenous repair in various ways that are discussed below (Franklin, 2002).

\section{PROLIFERATION OF OPCs}

In the adult demyelinating brain activated astrocytes and microglia secrete mitogens that induce OPC proliferation, such as the platelet-derived growth factor receptor-2A (PDGF-2A) and fibroblast growth factor-2 (FGF-2) (Franklin and ffrenchConstant, 2008; Clemente et al., 2013). The response of OPCs to mitogens is regulated by the cell cycle regulatory protein $\mathrm{p} 27-$ Kip1 (Crockett et al., 2005) and the cyclin-dependent kinase 2 (Caillava and Baron-Van Evercooren, 2012). In MS changes in the mitogenic environment induced by alterations in the levels of secreted factors might inhibit proliferation of OPCs (Franklin, 2002). Modulation of growth factor levels such as the FGF-2, was shown to enhance OPC proliferative activity in several in vitro models (Armstrong et al., 2002; Dziembowska et al., 2005).

\section{MIGRATION OF OPCS}

Animal studies showed that inflammation and demyelination promote migration of OPCs to the lesions (Nait-Oumesmar et al., 
1999; Piao et al., 2013). OPCs migrate to early inflammatory and chronic active MS lesions possibly being attracted by FGF2 expressed by infiltrating macrophages and microglia-derived macrophages (Clemente et al., 2011). In chronic inactive lesions however, formation of the characteristic glial scar composed of hypertrophic astrocytes, limits access of OPCs to the lesion center (Franklin and ffrench-Constant, 2008). Manipulation of chemotactic pathways such as the $\mathrm{C}-\mathrm{X}-\mathrm{C}$ chemokine receptor type 4, pharmacogenetic targets such as the FGF-2 and Anosmin-1, or guidance cues such as semaphorin-3A and $3 \mathrm{~F}$, might promote repopulation of MS lesions by OPCs, as it was shown in experimental in vivo or in vitro models for MS and in human MS brain tissue (Williams et al., 2007; Carbajal et al., 2010; Clemente et al., 2011).

\section{DIFFERENTIATION OF OPCs}

Demyelination influences the capacity of OPCs to differentiate by forming a "dysregulated" signaling environment. In chronic MS lesions, OPCs often acquire an immature phenotype which is not permissive for axon remyelination (Wolswijk, 2000). Events that inhibit OPC differentiation are the (1) Excessive accumulation of myelin fragments (Kotter et al., 2006), (2) Deposition of hyaluronan (Sloane et al., 2010), (3) Dysregulation of signaling pathways controlling cell fate, such as the $\mathrm{Wnt} / \beta$-catenin (Feigenson et al., 2011) and the Notch-Jagged pathway (John et al., 2002; Nakahara et al., 2009) and (4) Changes in levels of growth factors or bone morphogenic proteins (Franklin, 2002; Cheng et al., 2007). Pharmacological manipulation of therapeutic targets such as leucine rich repeat and Ig domain containing 1 (Jepson et al., 2012), retinoic X receptors (Huang et al., 2011), phosphodiesterase-7 (Medina-Rodríguez et al., 2013) and cyclindependent kinase 5 (Cdk5) (Luo et al., 2014) or signaling pathways such as the Fyn-Rho-ROCK and protein kinase C (PKC) (Baer et al., 2009) and the Notch/Jagged1 (Blanchard et al., 2013), can be advantageous for the repair of MS lesions.

\section{FUNCTION OF MATURE OLIGODENDROCYTES}

In the brain of MS patients, mature oligodendrocytes may undergo demyelination thereby losing capacity to myelinate (Wolswijk, 2000). Moreover, demyelinated axons may lose receptivity to myelination by oligodendrocytes due to re-expression of negative regulators, such as the polysialylated neural cell-adhesion molecule (PSA-NCAM) (Charles et al., 2002). These two or other events such as the reported reduction in astrocytic expression of neuregulins (Viehover et al., 2001) or the increased expression of insulin-like growth factor (IGF) binding proteins by oligodendrocytes (Wilczak et al., 2008), might prevent restoration of axon conduction properties in MS lesions. Pharmacological interventions to reverse those events might prove efficient in promoting repair of MS lesions (Lundgaard et al., 2013).

\section{REGENERATION BY NEW CELLS IN MS TARGETING OLIGODENDROCYTE REGENERATION}

Since sufficient levels of remyelination can repair damaged axons, stimulation of endogenous activity might be beneficial for repair of MS lesions. Besides activation of parenchymal OPCs, generation of new oligodendrocytes for the increase of brain remyelination activity appears a promising perspective for future therapies. This can be achieved with engraftment of transplanted cells or with stimulation of SVZ-derived NSCs by transplanted cells or growth factors to induce differentiation into OPCs.

\section{Stimulation of endogenous NSCs with cell transplantation}

Transplanted stem cells can boost remyelination by cell replacement or bystander neuroprotection and/or immunomodulation (Pluchino and Martino, 2008). Bystander effects induced by transplanted cells were shown to promote migration, differentiation and/or survival of endogenous NSCs thereby enhancing self-repair. The ideal cell types for transplantation in animal models of demyelination are the NSCs and mesenchymal stem cells (MSCs), while two other possible cell sources are the embryonic and induced pluripotent stem cells (iPSCs). The route of administration is an important factor determining the effect type and magnitude that cell transplantation induces. Mostly preferred routes for the delivery of MSCs or NSCs are the intravenous and intrathecal injections (Gianvito Martino, 2010). Administration of autologous MSCs in patients with progressive MS was shown to improve clinical outcome based on magnetic resonance imaging (MRI) examination while reported adverse effects were not significant (Laroni et al., 2013).

\section{Stimulation of endogenous NSCs with growth factors}

The new thrust in the treatment of MS is grounded on the discovery that NSCs persist within the adult healthy brain. The human SVZ is located at the lateral wall of the lateral ventricles, thereby providing an accessible route for the intracerebroventricular delivery of growth factors to activate NSC proliferation/differentiation. Newborn cells may theoretically replace the old damaged ones and promote repair in areas with poor regeneration. Intracerebroventricular application of growth factors have revealed multiple beneficial effects in EAE (Tafreshi, 2006).

The regeneration of MS lesions with new oligodendrocytes depends on the stage and location of the lesion. Although the role of inflammation in remyelination has not yet been clarified, our speculation is that repair of small newly-formed lesions might be advantageous over the repair of chronic lesions, in terms of reparative efficiency and energy consumption. Periventricular lesions are often present in MS and analyses of such lesions showed enhanced number of pro-migratory adhesion molecule PSANCAM+ progenitors expressing Sox9, Sox10, and/or Olig2 markers of glial fate. Concomitant enhancement of the PSA-NCAM+ progenitor population at the proximal SVZ suggested increased oligodendrogenesis (Nait-Oumesmar et al., 2007). These pieces of evidence indicate that regeneration of oligodendrocytes might be efficient in repairing lesions located near the SVZ, such as the corpus callosum (Figure 1). In accordance, recent evidence showed a four-fold increase in the number of NSC-derived oligodendrocytes expressing the PDGF receptor $\alpha$ and Olig2 markers of oligodendrocytes, in a single demyelinating lesion within the corpus callosum (Menn et al., 2006).

Interventions to modulate growth factor signaling for promoting oligodendrocyte replacement and remyelination are nowadays the focus of intense study. Both in vivo and in vitro experiments 


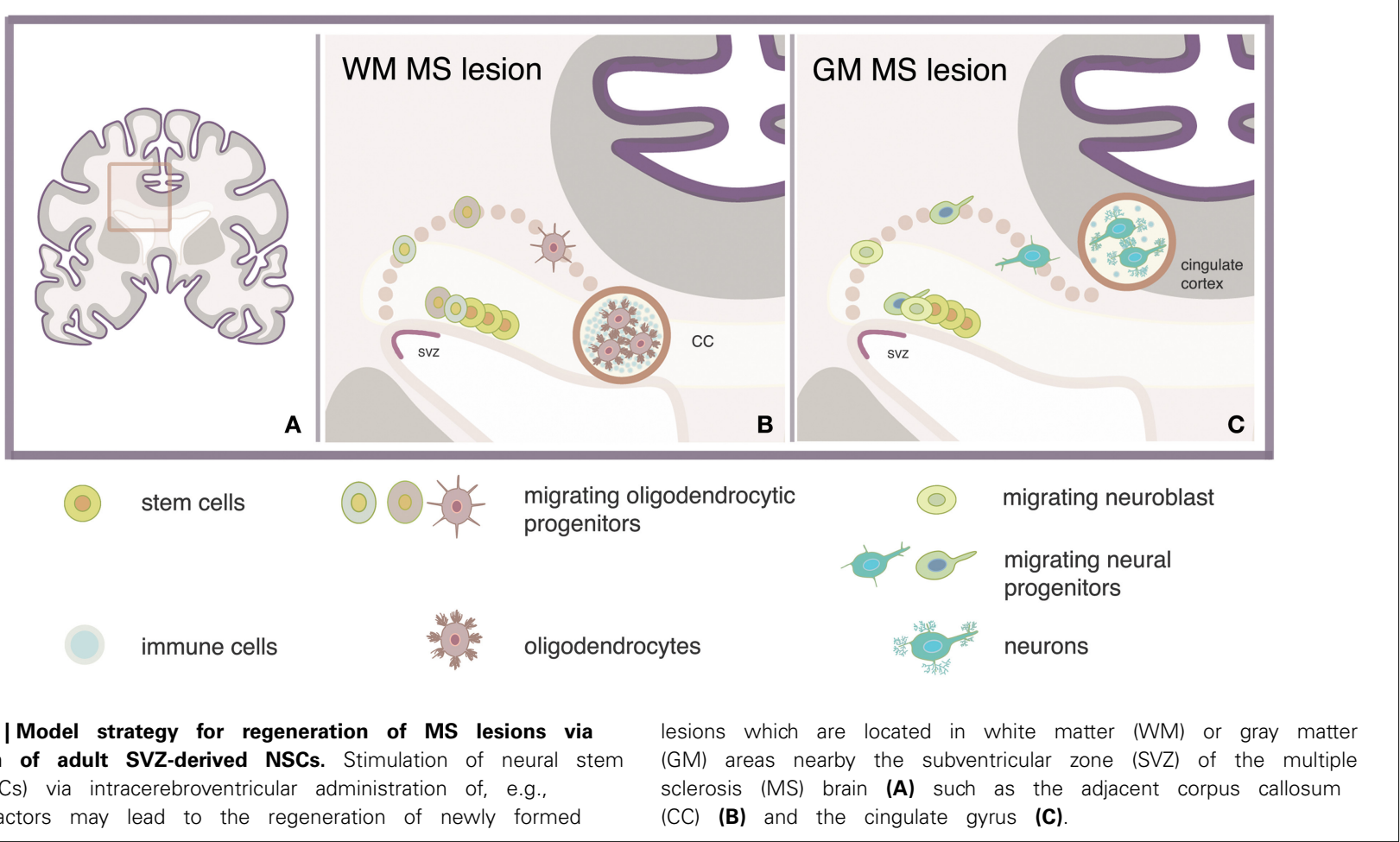

FIGURE 1 |Model strategy for regeneration of MS lesions via activation of adult SVZ-derived NSCs. Stimulation of neural stem cells (NSCs) via intracerebroventricular administration of, e.g., growth factors may lead to the regeneration of newly formed are or gray matte (CC) (B) and the cingulate gyrus (C)

Table 1 | Factors and secreted molecules activating the adult SVZ-derived NSCs, in animal models of demyelination.

\begin{tabular}{|c|c|c|c|c|}
\hline Factor & Model & Process & Function & References \\
\hline HB-EGF & LPC demyelinated mouse & $\mathrm{O}$ & Recruitment & Cantarella et al., 2008 \\
\hline FGF-2 & Cell culture & $\mathrm{O}$ & Recruitment & Clemente et al., 2011 \\
\hline CNTF & LPC demyelinated rodent & $\mathrm{O}$ & Recruitment & Vernerey et al., 2013 \\
\hline NGF & EAE rat & $\mathrm{O}$ & Differentiation & Aloe and Micera, 1998 \\
\hline IGF-1 & Cell culture & $N$ & Differentiation & Brooker et al., 2000 \\
\hline PEDF & Transgenic mouse & $\mathrm{O}$ & Fate commitment & Sohn et al., 2012 \\
\hline PDGF & Transgenic mouse & $\mathrm{O}$ & Proliferation & Jackson et al., 2006 \\
\hline VEGF & Unlesioned rat & $\mathrm{N}$ & Proliferation & Jin et al., 2002 \\
\hline BDNF & Unlesioned rat & $N$ & Proliferation & Pencea et al., 2001b \\
\hline \multicolumn{5}{|c|}{ MOLECULE } \\
\hline Reelin & LPC demyelinated mouse & $N$ & Recruitment & Courtès et al., 2011 \\
\hline Netrin 1 & LPC demyelinated mouse & $\mathrm{O}$ & Recruitment & Cayre et al., 2013 \\
\hline Chordin & LPC demyelinated mouse & $\mathrm{O}$ & Recruitment & Jablonska et al., 2010 \\
\hline \multirow[t]{2}{*}{ Noggin } & Cuprizone demyelinated mouse & 0 & Proliferation & Cate et al., 2010 \\
\hline & & & Fate commitment & \\
\hline
\end{tabular}

LPC, Lysolecithin; O, Oligodendrogenesis; N, Neurogenesis; EAE, experimental autoimmune encephalomyelitis; HB-EGF, Heparin-binding epidermal growth factor;

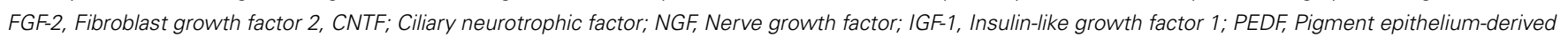
factor; PDGF, Platelet-derived growth factor; VEGF, Vascular endothelial growth factor; BDNF, Brain-derived neurotrophic factor.

revealed various factors which act on OPCs derived by the adult SVZ, and influence proliferation, migration or differentiation properties (Table 1). An advanced candidate for MS is IGF-1, a factor previously shown to delay EAE onset and improve clinical outcome (Zhang et al., 2011). In a pilot trial, seven MS patients were treated with subcutaneous administration of recombinant (rh) IGF-1 over a 6-month period of time. The peripheral administration of rhIGF-1 had no significant adverse effects. However,
MRI examination of patients after treatment showed no significant clinical improvement. Explanations for the absence of positive effects on clinical outcome were the small sample size and the limited penetration of rhIGF-1 across the BBB (Frank et al., 2002). Since surgically invasive procedures are not applicable in human trials, intranasal administration of growth factors might represent an interesting alternative approach for successful delivery inside the CNS (Hanson and Frey, 2008). 


\section{TARGETING NEURONAL REGENERATION}

The confirmed existence of OPCs in the adult brain as well as the increasing understanding of the pathways regulating endogenous remyelination, are the basic reasons why regeneration of oligodendrocytes is a more well investigated approach compared to regeneration of neurons. Replacement of damaged neurons however, is anticipated to offer intriguing possibilities for the rehabilitation of cognitive disturbances in patients with progressive MS. New neurons may repopulate focal sites of degeneration located near the SVZ, such as the OB or the cingulate gyrus, to induce repair, contributing to the re-growth of nerves that have been lost (Figure 1).

Challenges associated with that strategy are linked to the type, density and ability of new neurons to integrate into defined circuits. Acquisition of specific neuronal subtypes is a demanding step for neuronal regeneration of MS lesions since recent evidence indicated heterogeneity and reduced neuropotency in the population of adult SVZ-derived NSCs (Shen et al., 2006). Moreover, the ability of new neurons to functionally mature at the sites of damage is still debated because the sites of lesions are normally non-neurogenic (Obernier et al., 2014). For the expansion of new neurons, and promotion of maturation, specific growth factors can be administered at the SVZ (Table 1). The possibility that new neurons are poorly myelinated due to lack of oligodendrocytes has to be studied. Importantly, the extraordinary proliferation or direction of SVZ-derived NSCs toward neuronal phenotypes other than the ones they were intrinsically committed for might induce unwanted effects linked to tumorigenesis. Monitoring and quantification of NSC activation is required and can be conducted with non-invasive techniques, such as the positron emission tomography (Rueger et al., 2010).

\section{CONCLUSION}

Stimulation of endogenous NSCs with growth factors is an interesting approach for treatment of MS and requires more research in order to reveal its entire therapeutic potential. An important question that needs to be addressed is if this approach can repair all or subtypes of MS lesions depending on whether the damage is focal or diffuse. Notably, MS is a complex disease showing activity even in late progressive phases. Therefore, even if regeneration with NSCs proves efficient to revert damage in the CNS of MS patients that today is considered to be irreversible, a combination with disease modifying agents might be needed to halt MS progression.

\section{ACKNOWLEDGMENTS}

We would like to thank Georgia Michailidou for the illustration of our hypothesis on the repair of multiple sclerosis lesions with endogenous neural stem cells. This work was supported by the "van Leersumfonds" (VLF2013265) to Miriam E. van Strien.

\section{REFERENCES}

Aloe, L., and Micera, A. (1998). A role of nerve growth factor in oligodendrocyte growth and differentiation of EAE affected rats. Arch. Ital. Biol. 136, 247-256.

Andersson, P. B., Waubant, E., Gee, L., and Goodkin, D. E. (1999). Multiple sclerosis that is progressive from the time of onset: clinical characteristics and progression of disability. Arch. Neurol. 56, 1138-1142. doi: 10.1001/archneur.56. 9.1138
Armstrong, R. C., Le, T. Q., Frost, E. E., Borke, R. C., and Vana, A. C. (2002). Absence of fibroblast growth factor 2 promotes oligodendroglial repopulation of demyelinated white matter. J. Neurosci. Off. J. Soc. Neurosci. 22, 8574-8585.

Baer, A. S., Syed, Y. A., Kang, S. U., Mitteregger, D., Vig, R., Ffrench-Constant, C., et al. (2009). Myelin-mediated inhibition of oligodendrocyte precursor differentiation can be overcome by pharmacological modulation of FynRhoA and protein kinase C signalling. Brain J. Neurol. 132, 465-481. doi: 10.1093/brain/awn334

Barak, Y., and Achiron, A. (2002). Effect of interferon-beta-lb on cognitive functions in multiple sclerosis. Eur. Neurol. 47, 11-14. doi: 10.1159/0000 47940

Blakemore, W. F., and Keirstead, H. S. (1999). The origin of remyelinating cells in the central nervous system. J. Neuroimmunol. 98, 69-76. doi: 10.1016/S01655728(99)00083-1

Blanchard, B., Heurtaux, T., Garcia, C., Moll, N. M., Caillava, C., Grandbarbe, L., et al. (2013). Tocopherol derivative TFA-12 promotes myelin repair in experimental models of multiple sclerosis. J. Neurosci. 33, 11633-11642. doi: 10.1523/JNEUROSCI.0774-13.2013

Brooker, G. J., Kalloniatis, M., Russo, V. C., Murphy, M., Werther, G. A., and Bartlett, P. F. (2000). Endogenous IGF-1 regulates the neuronal differentiation of adult stem cells. J. Neurosci. Res. 59, 332-341. doi: 10.1002/(SICI) 10974547(20000201)59:3<332::AID-JNR6>3.0.CO;2-2

Caillava, C., and Baron-Van Evercooren, A. (2012). Differential requirement of cyclin-dependent kinase 2 for oligodendrocyte progenitor cell proliferation and differentiation. Cell Div. 7:14. doi: 10.1186/1747-1028-7-14

Cameron, H. A., and Gould, E. (1994). Adult neurogenesis is regulated by adrenal steroids in the dentate gyrus. Neuroscience 61, 203-209. doi: 10.1016/03064522(94)90224-0

Cantarella, C., Cayre, M., Magalon, K., and Durbec, P. (2008). Intranasal HBEGF administration favors adult SVZ cell mobilization to demyelinated lesions in mouse corpus callosum. Dev. Neurobiol. 68, 223-236. doi: 10.1002/dneu. 20588

Carbajal, K. S., Schaumburg, C., Strieter, R., Kane, J., and Lane, T. E. (2010). Migration of engrafted neural stem cells is mediated by CXCL12 signaling through CXCR4 in a viral model of multiple sclerosis. Proc. Natl. Acad. Sci. U.S.A. 107, 11068-11073. doi: 10.1073/pnas.1006375107

Carleton, A., Petreanu, L. T., Lansford, R., Alvarez-Buylla, A., and Lledo, P.-M. (2003). Becoming a new neuron in the adult olfactory bulb. Nat. Neurosci. 6 , 507-518. doi: 10.1038/nn1048

Cate, H. S., Sabo, J. K., Merlo, D., Kemper, D., Aumann, T. D., Robinson, J., et al. (2010). Modulation of bone morphogenic protein signalling alters numbers of astrocytes and oligodendroglia in the subventricular zone during cuprizoneinduced demyelination. J. Neurochem. 115, 11-22. doi: 10.1111/j.14714159.2010.06660.x

Cayre, M., Courtès, S., Martineau, F., Giordano, M., Arnaud, K., Zamaron, A., et al. (2013). Netrin 1 contributes to vascular remodeling in the subventricular zone and promotes progenitor emigration after demyelination. Dev. Camb. Engl. 140, 3107-3117. doi: 10.1242/dev.092999

Chang, A., Smith, M. C., Yin, X., Fox, R. J., Staugaitis, S. M., and Trapp, B. D. (2008). Neurogenesis in the chronic lesions of multiple sclerosis. Brain J. Neurol. 131, 2366-2375. doi: 10.1093/brain/awn157

Charles, P., Reynolds, R., Seilhean, D., Rougon, G., Aigrot, M. S., Niezgoda, A., et al. (2002). Re-expression of PSA-NCAM by demyelinated axons: an inhibitor of remyelination in multiple sclerosis? Brain 125, 1972-1979. doi: 10.1093/brain/awf216

Cheng, X., Wang, Y., He, Q., Qiu, M., Whittemore, S. R., and Cao, Q. (2007). Bone morphogenetic protein signaling and olig1/2 interact to regulate the differentiation and maturation of adult oligodendrocyte precursor cells. Stem Cells Dayt. Ohio 25, 3204-3214. doi: 10.1634/stemcells. 2007-0284

Clemente, D., Ortega, M. C., Arenzana, F. J., and de Castro, F. (2011). FGF-2 and Anosmin-1 are selectively expressed in different types of multiple sclerosis lesions. J. Neurosci. 31, 14899-14909. doi: 10.1523/JNEUROSCI.115811.2011

Clemente, D., Ortega, M. C., Melero-Jerez, C., and de Castro, F. (2013). The effect of glia-glia interactions on oligodendrocyte precursor cell biology during development and in demyelinating diseases. Front. Cell. Neurosci. 7:268. doi: 10.3389/fncel.2013.00268 
Coles, A. J., Cox, A., Le Page, E., Jones, J., Trip, S. A., Deans, J., et al. (2006). The window of therapeutic opportunity in multiple sclerosis: evidence from monoclonal antibody therapy. J. Neurol. 253, 98-108. doi: 10.1007/s00415-005-0934-5

Compston, A., and Coles, A. (2002). Multiple sclerosis. Lancet 359, 1221-1231. doi: 10.1016/S0140-6736(02)08220-X

Compston, A., Zajicek, J., Sussman, J., Webb, A., Hall, G., Muir, D., et al. (1997). Glial lineages and myelination in the central nervous system. J. Anat. 190 (Pt 2), 161-200. doi: 10.1046/j.1469-7580.1997.19020161.x

Courtès, S., Vernerey, J., Pujadas, L., Magalon, K., Cremer, H., Soriano, E., et al. (2011). Reelin controls progenitor cell migration in the healthy and pathological adult mouse brain. PLoS ONE 6:e20430. doi: 10.1371/journal.pone.00 20430

Craig, C. G., D’sa, R., Morshead, C. M., Roach, A., and van der Kooy, D. (1999). Migrational analysis of the constitutively proliferating subependyma population in adult mouse forebrain. Neuroscience 93, 1197-1206.

Crockett, D. P., Burshteyn, M., Garcia, C., Muggironi, M., and Casaccia-Bonnefil, P. (2005). Number of oligodendrocyte progenitors recruited to the lesioned spinal cord is modulated by the levels of the cell cycle regulatory protein p27Kip-1. Glia 49, 301-308. doi: 10.1002/glia.20111

Dziembowska, M., Tham, T. N., Lau, P., Vitry, S., Lazarini, F., and Dubois-Dalcq, M. (2005). A role for CXCR4 signaling in survival and migration of neural and oligodendrocyte precursors. Glia 50, 258-269. doi: 10.1002/glia.20170

Feigenson, K., Reid, M., See, J., Crenshaw, E. B. III., and Grinspan, J. B. (2011). Canonical Wnt signalling requires the BMP pathway to inhibit oligodendrocyte maturation. ASN Neuro 3, 147-158. doi: 10.1042/AN20110004

Fischer, J. S., Priore, R. L., Jacobs, L. D., Cookfair, D. L., Rudick, R. A., Herndon, R. M., et al. (2000). Neuropsychological effects of interferon beta-1a in relapsing multiple sclerosis. Multiple sclerosis collaborative research group. Ann. Neurol. 48, 885-892. doi: 10.1002/1531-8249(200012)48:6<885::AIDANA9 $>3.0 . \mathrm{CO} ; 2-1$

Frank, J., Richert, N., Lewis, B., Bash, C., Howard, T., Civil, R., et al. (2002). A pilot study of recombinant insulin-like growth factor-1 in seven multiple sderosis patients. Mult. Scler. 8, 24-29. doi: 10.1191/1352458502ms768oa

Franklin, R. J. M. (2002). Why does remyelination fail in multiple sclerosis? Nat. Rev. Neurosci. 3, 705-714. doi: 10.1038/nrn917

Franklin, R. J. M., and ffrench-Constant, C. (2008). Remyelination in the CNS: from biology to therapy. Nat. Rev. Neurosci. 9, 839-855. doi: 10.1038/ nrn 2480

Gage, F. H. (2000). Mammalian neural stem cells. Science 287, 1433-1438. doi: 10.1126/science.287.5457.1433

Gage, F. H., Kempermann, G., Palmer, T. D., Peterson, D. A., and Ray, J. (1998). Multipotent progenitor cells in the adult dentate gyrus. J. Neurobiol. 36, 249-266.

Gensert, J. M., and Goldman, J. E. (1997). Endogenous progenitors remyelinate demyelinated axons in the adult CNS. Neuron 19, 197-203. doi: 10.1016/S08966273(00)80359-1

Geurts, J. J., and Barkhof, F. (2008). Grey matter pathology in multiple sclerosis. Lancet Neurol. 7, 841-851. doi: 10.1016/S1474-4422(08)70191-1

Gianvito Martino, R. J. M. F. (2010). Stem cell transplantation in multiple sclerosis: current status and future prospects. Nat. Rev. Neurol. 6, 247-255. doi: 10.1038/nrneurol.2010.35

Goldschmidt, T., Antel, J., König, F. B., Brück, W., and Kuhlmann, T. (2009). Remyelination capacity of the MS brain decreases with disease chronicity. Neurology 72, 1914-1921. doi: 10.1212/WNL.0b013e3181a8260a

Goodin, D. S., Frohman, E. M., Garmany, G. P. Jr., Halper, J., Likosky, W. H., Lublin, F. D., et al. (2002). Disease modifying therapies in multiple sclerosis: report of the therapeutics and technology assessment subcommittee of the American academy of neurology and the MS council for clinical practice guidelines. Neurology 58, 169-178. doi: 10.1212/WNL.58.2.169

Hanson, L. R., and Frey, W. H. (2008). Intranasal delivery bypasses the blood-brain barrier to target therapeutic agents to the central nervous system and treat neurodegenerative disease. BMC Neurosci. 9:S5. doi: 10.1186/1471-2202-9-S3-S5

Hemmer, B., Nessler, S., Zhou, D., Kieseier, B., and Hartung, H.-P. (2006). Immunopathogenesis and immunotherapy of multiple sclerosis. Nat. Clin. Pract. Neurol. 2, 201-211. doi: 10.1038/ncpneuro0154

Huang, J. K., Jarjour, A. A., Oumesmar, B. N., Kerninon, C., Williams, A., Krezel, W., et al. (2011). Retinoid X receptor gamma signaling accelerates CNS remyelination. Nat. Neurosci. 14, 45-53. doi: 10.1038/nn.2702
Jablonska, B., Aguirre, A., Raymond, M., Szabo, G., Kitabatake, Y., Sailor, K. A., et al. (2010). Chordin-induced lineage plasticity of adult SVZ neuroblasts after demyelination. Nat. Neurosci. 13, 541-550. doi: 10.1038/nn.2536

Jackson, E. L., Garcia-Verdugo, J. M., Gil-Perotin, S., Roy, M., Quinones-Hinojosa, A., VandenBerg, S., et al. (2006). PDGFR alpha-positive B cells are neural stem cells in the adult SVZ that form glioma-like growths in response to increased PDGF signaling. Neuron 51, 187-199. doi: 10.1016/j.neuron.2006.06.012

Jacobson, M. (1991). Developmental Neurobiology. New York, NY: The New England Journal of Medicine. doi: 10.1007/978-1-4757-4954-0

Jepson, S., Vought, B., Gross, C. H., Gan, L., Austen, D., Frantz, J. D., et al. (2012). LINGO-1, a transmembrane signaling protein, inhibits oligodendrocyte differentiation and myelination through intercellular self-interactions. J. Biol. Chem. 287, 22184-22195. doi: 10.1074/jbc.M112.366179

Jin, K., Zhu, Y., Sun, Y., Mao, X. O., Xie, L., and Greenberg, D. A. (2002). Vascular endothelial growth factor (VEGF) stimulates neurogenesis in vitro and in vivo. Proc. Natl. Acad. Sci. U.S.A. 99, 11946-11950. doi: 10.1073/pnas.182296499

John, G. R., Shankar, S. L., Shafit-Zagardo, B., Massimi, A., Lee, S. C., Raine, C. S., et al. (2002). Multiple sclerosis: re-expression of a developmental pathway that restricts oligodendrocyte maturation. Nat. Med. 8, 1115-1121. doi: $10.1038 / \mathrm{nm} 781$

Kotter, M. R., Li, W.-W., Zhao, C., and Franklin, R. J. M. (2006). Myelin impairs CNS remyelination by inhibiting oligodendrocyte precursor cell differentiation. J. Neurosci. Off. J. Soc. Neurosci. 26, 328-332. doi: 10.1523/JNEUROSCI.261505.2006

Laroni, A., Novi, G., de Rosbo, N. K., and Uccelli, A. (2013). Towards Clinical Application of mesenchymal stem cells for treatment of neurological diseases of the central nervous system. J. Neuroimmune Pharmacol. Off. J. Soc. Neuroimmune Pharmacol. 8, 1062-1076. doi: 10.1007/s11481-013-9456-6

Lee, J. C., Mayer-Proschel, M., and Rao, M. S. (2000). Gliogenesis in the central nervous system. Glia 30, 105-121. doi: 10.1002/(SICI) 10981136(200004)30:2<105::AID-GLIAl>3.0.CO;2-H

Leonard, B. W., Mastroeni, D., Grover, A., Liu, Q., Yang, K., Gao, M., et al. (2009). Subventricular zone neural progenitors from rapid brain autopsies of elderly subjects with and without neurodegenerative disease. J. Comp. Neurol. 515, 269-294. doi: 10.1002/cne.22040

Lois, C., García-Verdugo, J. M., and Alvarez-Buylla, A. (1996). Chain migration of neuronal precursors. Science 271, 978-981. doi: 10.1126/science.271.52 51.978

Lublin, F. D., and Reingold, S. C. (1996). Defining the clinical course of multiple sclerosis: results of an international survey. National multiple sclerosis society (USA) advisory committee on clinical trials of new agents in multiple sclerosis. Neurology 46, 907-911. doi: 10.1212/WNL.46.4.907

Lundgaard, I., Luzhynskaya, A., Stockley, J. H., Wang, Z., Evans, K. A., Swire, M., et al. (2013). Neuregulin and BDNF induce a switch to NMDA receptordependent myelination by oligodendrocytes. PLoS Biol. 11:e1001743. doi: 10.1371/journal.pbio.1001743

Luo, F., Burke, K., Kantor, C., Miller, R. H., and Yang, Y. (2014). Cyclindependent kinase 5 mediates adult OPC maturation and myelin repair through modulation of Akt and GsK-3 signaling. J. Neurosci. 34, 10415-10429. doi: 10.1523/JNEUROSCI.0710-14.2014

Medina-Rodríguez, E. M., Arenzana, F. J., Pastor, J., Redondo, M., Palomo, V., García de Sola, R., et al. (2013). Inhibition of endogenous phosphodiesterase 7 promotes oligodendrocyte precursor differentiation and survival. Cell. Mol. Life Sci. 70, 3449-3462. doi: 10.1007/s00018-013-1340-2

Menn, B., Garcia-Verdugo, J. M., Yaschine, C., Gonzalez-Perez, O., Rowitch, D., and Alvarez-Buylla, A. (2006). Origin of oligodendrocytes in the subventricular zone of the adult brain. J. Neurosci. 26, 7907-7918. doi: 10.1523/JNEUROSCI.129906.2006

Molyneux, P. D., Kappos, L., Polman, C., Pozzilli, C., Barkhof, F., Filippi, M., et al. (2000). The effect of interferon beta-1b treatment on MRI measures of cerebral atrophy in secondary progressive multiple sclerosis. European Study Group on Interferon beta- $1 \mathrm{~b}$ in secondary progressive multiple sclerosis. Brain J. Neurol. 123 (Pt 11), 2256-2263. doi: 10.1093/brain/123.11.2256

Nader Sanai, A. D. T. (2004). Unique astrocyte ribbon in adult human brain contains neural stem cells but lacks chain migration. Nature 427, 740-744. doi: 10.1038/nature02301

Nait-Oumesmar, B., Decker, L., Lachapelle, F., Avellana-Adalid, V., Bachelin, C., and Baron-Van Evercooren, A. (1999). Progenitor cells of the adult mouse 
subventricular zone proliferate, migrate and differentiate into oligodendrocytes after demyelination. Eur. J. Neurosci. 11, 4357-4366. doi: 10.1046/j.14609568.1999.00873.x

Nait-Oumesmar, B., Picard-Riera, N., Kerninon, C., Decker, L., Seilhean, D., Höglinger, G. U., et al. (2007). Activation of the subventricular zone in multiple sclerosis: evidence for early glial progenitors. Proc. Natl. Acad. Sci. U.S.A. 104, 4694-4699. doi: 10.1073/pnas.0606835104

Nakahara, J., Kanekura, K., Nawa, M., Aiso, S., and Suzuki, N. (2009). Abnormal expression of TIP30 and arrested nucleocytoplasmic transport within oligodendrocyte precursor cells in multiple sclerosis. J. Clin. Invest. 119, 169-181. doi: $10.1172 / \mathrm{JCI} 35440$

Noseworthy, J. H., Lucchinetti, C., Rodriguez, M., and Weinshenker, B. G. (2000). Multiple sclerosis. N. Engl. J. Med. 343, 938-952. doi: 10.1056/NEJM200009283431307

Obernier, K., Tong, C. K., and Alvarez-Buylla, A. (2014). Restricted nature of adult neural stem cells: re-evaluation of their potential for brain repair. Neurogenesis 8:162. doi: $10.3389 /$ fnins.2014.00162

Patani, R., Balaratnam, M., Vora, A., and Reynolds, R. (2007). Remyelination can be extensive in multiple sclerosis despite a long disease course. Neuropathol. Appl. Neurobiol. 33, 277-287. doi: 10.1111/j.1365-2990.2007. 00805.x

Pencea, V., Bingaman, K. D., Freedman, L. J., and Luskin, M. B. (2001a). Neurogenesis in the subventricular zone and rostral migratory stream of the neonatal and adult primate forebrain. Exp. Neurol. 172, 1-16. doi: 10.1006/exnr.2001.7768

Pencea, V., Bingaman, K. D., Wiegand, S. J., and Luskin, M. B. (2001b). Infusion of brain-derived neurotrophic factor into the lateral ventricle of the adult rat leads to new neurons in the parenchyma of the striatum, septum, thalamus, and hypothalamus. J. Neurosci. Off. J. Soc. Neurosci. 21, 6706-6717.

Piao, J.-H., Wang, Y., and Duncan, I. D. (2013). CD44 is required for the migration of transplanted oligodendrocyte progenitor cells to focal inflammatory demyelinating lesions in the spinal cord. Glia 61, 361-367. doi: 10.1002/glia. 22438

Picard-Riera, N., Decker, L., Delarasse, C., Goude, K., Nait-Oumesmar, B., Liblau, R., et al. (2002). Experimental autoimmune encephalomyelitis mobilizes neural progenitors from the subventricular zone to undergo oligodendrogenesis in adult mice. Proc. Natl. Acad. Sci. U.S.A. 99, 13211-13216. doi: 10.1073/pnas.192314199

Pluchino, S., and Martino, G. (2008). The therapeutic plasticity of neural stem/precursor cells in multiple sclerosis. J. Neurol. Sci. 265, 105-110. doi: 10.1016/j.jns.2007.07.020

Quiñones-Hinojosa, A., Sanai, N., Gonzalez-Perez, O., and Garcia-Verdugo, J. M. (2007). The human brain subventricular zone: stem cells in this niche and its organization. Neurosurg. Clin. N. Am. 18, 15-20. doi: 10.1016/j.nec.2006. 10.013

Roosendaal, S. D., Hulst, H. E., Vrenken, H., Feenstra, H. E. M., Castelijns, J. A., Pouwels, P. J. W., et al. (2010). Structural and functional hippocampal changes in multiple sclerosis patients with intact memory function. Radiology 255, 595-604. doi: 10.1148/radiol.10091433

Rueger, M. A., Backes, H., Walberer, M., Neumaier, B., Ullrich, R., Simard, M.-L., et al. (2010). Noninvasive Imaging of endogenous neural stem cell mobilization in vivo using positron emission tomography. J. Neurosci. 30, 6454-6460. doi: 10.1523/JNEUROSCI.6092-09.2010

Sanai, N., Nguyen, T., Ihrie, R. A., Mirzadeh, Z., Tsai, H.-H., Wong, M., et al. (2011). Corridors of migrating neurons in the human brain and their decline during infancy. Nature 478, 382-386. doi: 10.1038/nature10487

Shen, Q., Wang, Y., Dimos, J. T., Fasano, C. A., Phoenix, T. N., Lemischka, I. R., et al. (2006). The timing of cortical neurogenesis is encoded within lineages of individual progenitor cells. Nat. Neurosci. 9, 743-751. doi: 10.1038/ nn1694

Sloane, J. A., Batt, C., Ma, Y., Harris, Z. M., Trapp, B., and Vartanian, T. (2010). Hyaluronan blocks oligodendrocyte progenitor maturation and remyelination through TLR2. Proc. Natl. Acad. Sci. U.S.A. 107, 11555-11560. doi: 10.1073/pnas.1006496107

Sohn, J., Selvaraj, V., Wakayama, K., Orosco, L., Lee, E., Crawford, S. E., et al. (2012). PEDF Is a novel oligodendrogenic morphogen acting on the adult SVZ and corpus callosum. J. Neurosci. 32, 12152-12164. doi: 10.1523/JNEUROSCI.0628-12.2012

Sospedra, M., and Martin, R. (2005). Immunology of multiple sclerosis. Annu. Rev. Immunol. 23, 683-747. doi: 10.1146/annurev.immunol.23.021704. 115707

Sun, J., Zhou, W., Ma, D., and Yang, Y. (2010). Endothelial cells promote neural stem cell proliferation and differentiation associated with VEGF activated Notch and Pten signaling. Dev. Dyn. Off. Publ. Am. Assoc. Anat. 239, 2345-2353. doi: $10.1002 /$ dvdy.22377

Tafreshi, A. P. (2006). Nerve growth factor prevents demyelination, cell death and progression of the disease in experimental allergic encephalomyelitis. Iran J. Allergy Asthma Immunol. 5, 177-181.

Tepavčević, V., Lazarini, F., Alfaro-Cervello, C., Kerninon, C., Yoshikawa, K., Garcia-Verdugo, J. M., et al. (2011). Inflammation-induced subventricular zone dysfunction leads to olfactory deficits in a targeted mouse model of multiple sclerosis. J. Clin. Invest. 121, 4722-4734. doi: 10.1172/ JCI59145

Trapp, B. D., Peterson, J., Ransohoff, R. M., Rudick, R., Mörk, S., and Bö, L. (1998). Axonal transection in the lesions of multiple sclerosis. N. Engl. J. Med. 338, 278-285. doi: 10.1056/NEJM199801293380502

Van den Berge, S. A., Middeldorp, J., Zhang, C. E., Curtis, M. A., Leonard, B. W., Mastroeni, D., et al. (2010). Longterm quiescent cells in the aged human subventricular neurogenic system specifically express GFAP-delta. Aging Cell 9, 313-326. doi: 10.1111/j.1474-9726.2010.00556.x

Van den Berge, S. A., van Strien, M. E., Korecka, J. A., Dijkstra, A. A., Sluijs, J. A., Kooijman, L., et al. (2011). The proliferative capacity of the subventricular zone is maintained in the parkinsonian brain. Brain J. Neurol. 134, 3249-3263. doi: $10.1093 /$ brain/awr256

Van Strien, M. E., van den Berge, S. A., and Hol, E. M. (2011). Migrating neuroblasts in the adult human brain: a stream reduced to a trickle. Cell Res. 21, 1523-1525. doi: 10.1038/cr.2011.101

Vernerey, J., Macchi, M., Magalon, K., Cayre, M., and Durbec, P. (2013). Ciliary Neurotrophic factor controls progenitor migration during remyelination in the adult rodent brain. J. Neurosci. 33, 3240-3250. doi: 10.1523/JNEUROSCI.257912.2013

Viehover, A., Miller, R. H., Park, S. K., Fischbach, G., and Vartanian, T. (2001). Neuregulin: an oligodendrocyte growth factor absent in active multiple sclerosis lesions. Dev. Neurosci. 23, 377-386. doi: 10.1159/000048721

Vogel, D. Y., Vereyken, E. J., Glim, J. E., Heijnen, P. D., Moeton, M., Valk, P., et al. (2013). Macrophages in inflammatory multiple sclerosis lesions have an intermediate activation status. J. Neuroinflammation 10:35. doi: 10.1186/17422094-10-35

Wilczak, N., Chesik, D., Hoekstra, D., and De Keyser, J. (2008). IGF binding protein alterations on periplaque oligodendrocytes in multiple sclerosis: implications for remyelination. Neurochem. Int. 52, 1431-1435. doi: 10.1016/j.neuint.2008.03.004

Williams, A., Piaton, G., Aigrot, M.-S., Belhadi, A., Théaudin, M., Petermann, F., et al. (2007). Semaphorin 3A and 3F: key players in myelin repair in multiple sclerosis? Brain J. Neurol. 130, 2554-2565. doi: 10.1093/brain/ awm202

Wilson, P. G., and Stice, S. S. (2006). Development and differentiation of neural rosettes derived from human embryonic stem cells. Stem Cell Rev. 2, 67-77. doi: 10.1007/s12015-006-0011-1

Wolswijk, G. (1998). Chronic stage multiple sclerosis lesions contain a relatively quiescent population of oligodendrocyte precursor cells. J. Neurosci. Off. J. Soc. Neurosci. 18, 601-609.

Wolswijk, G. (2000). Oligodendrocyte survival, loss and birth in lesions of chronic-stage multiple sclerosis. Brain 123, 105-115. doi: 10.1093/brain/123. 1.105

Young, K. M., Psachoulia, K., Tripathi, R. B., Dunn, S.-J., Cossell, L., Attwell, D., et al. (2013). Oligodendrocyte dynamics in the healthy adult CNS: evidence for myelin remodeling. Neuron 77, 873-885. doi: 10.1016/j.neuron.2013. 01.006

Zhang, J., Kramer, E. G., Mahase, S., Dutta, D. J., Bonnamain, V., Argaw, A. T., et al. (2011). Targeting oligodendrocyte protection and remyelination in multiple sclerosis. Mt. Sinai J. Med. J. Transl. Pers. Med. 78, 244-257. doi: $10.1002 / \mathrm{msj} .20244$ 
Conflict of Interest Statement: The authors declare that the research was conducted in the absence of any commercial or financial relationships that could be construed as a potential conflict of interest.

Received: 15 September 2014; accepted: 22 December 2014; published online: 20 January 2015.

Citation: Michailidou I, de Vries HE, Hol EM and van Strien ME (2015) Activation of endogenous neural stem cells for multiple sclerosis therapy. Front. Neurosci. 8:454. doi: 10.3389/fnins.2014.00454
This article was submitted to Neurogenesis, a section of the journal Frontiers in Neuroscience.

Copyright (C) 2015 Michailidou, de Vries, Hol and van Strien. This is an openaccess article distributed under the terms of the Creative Commons Attribution License (CC BY). The use, distribution or reproduction in other forums is permitted, provided the original author(s) or licensor are credited and that the original publication in this journal is cited, in accordance with accepted academic practice. No use, distribution or reproduction is permitted which does not comply with these terms. 